\title{
A Teoria do Trabalho e as Preferências de Remuneração a partir de uma Perspectiva Austríaca*
}

\author{
Martín Krause ${ }^{* *}$
}

\begin{abstract}
Resumo: A teoria econômica dos recursos humanos possibilita uma melhor compreensão dos sistemas de remuneração em face dos problemas gerados pela relação principal - agente, em que os indivíduos buscam a satisfação de seus interesses pessoais, o que torna necessário um mecanismo que promova o alinhamento dos interesses no interior das organizações. O prosseguimento dos estudos nessa área acabou determinando uma simplificação dos pressupostos da teoria. A teoria econômica da Escola Austríaca, ao enfatizar o valor subjetivo e a criatividade empresarial, fornece o aparato conceitual apropriado para a análise das preferências dos indivíduos em matéria de incentivos.
\end{abstract}

Palavras-Chave: Teoria do trabalho, Escola Austríaca de Economia, Remuneração, Incentivos, Pecuniários, Não Pecuniários, Valor Subjetivo, Heterogeneidade.

\section{Austrian Labor Theory and Preferences Over Compensation}

\begin{abstract}
Personnel Economics has allowed us to better understand compensation schemes in face of the problems coming out of the principal-agent relationship, with individuals pursuing their own private interests making necessary a mechanism to promote the alignment of interests within the organization. The theory had to simplify its assumptions. Austrian Economics Theory, emphasizing subjective value and entrepreneurial creativity gives a convenient background to consider individuals' preferences over incentives.
\end{abstract}

Keywords: Labor Theory, Austrian Economics, Compensation, Incentives, Monetary, Non-monetary; Subjective Value; Heterogeneity.

Classificação JEL: B53; D86; J00; J3; J33; M12; M52

\footnotetext{
" O presente artigo foi elaborado com exclusividade para a MISES: Revista Interdisciplinar de Filosofia, Direito e Economia. Traduzido do original inglês para o português por Evandro Ferreira e Silva.

** Martin Krause é professor titular de Economia da Facultad de Derecho y Ciencias Sociales e professor adjunto de História do Pensamento Econômico na Universidad de Buenos Aires (UBA), na Argentina, professor visitante de Economia Institucional na Universidad Francisco Marroquín (UFM), na Guatemala, professor visitante da Swiss Management Center, na Suíça, pesquisador adjunto do Cato Institute, nos Estados Unidos, e membro da Mont Pelerin Society. Cursou a graduação em Contabilidade Pública na UBA e o doutorado em Administração na Universidad Católica de La Plata. Foi professor titular de Políticas Econômicas e Políticas Públicas da ESEADE, onde, também, ocupo as funções de Centro de Investigaciones de Instituciones y Mercados de Argentina (CIIMA), vice-reitor e reitor. Atuou como diretor executivo da Fundación Libertad y Democracia e consultor de comércio exterior da subsecretaria de indústria do ministério da economia na província de Buenos Aires. É autor de diferentes artigos em revistas acadêmicas publicados na América Latina, nos Estados Unidos e na Europa, bem como dos Proyectos por una sociedad abierta (Abeledo-Perrot, 1993), Democracia directa (Abeledo-Perrot, 1997), En defensa de los más necesitados (Atlántida, 1998), La economía explicada a mis hijos (Aguilar, 2003), Economía para emprendedores (Aguilar, 2004), Análisis Económico del Derecho: Aplicación a Fallos Judiciales (La Ley, 2006), Por el ojo de una aguja: Ética, negocios y dinero en el mundo de hoy (Aguilar, 2007), Elementos de Economía Política (La Ley, 2007) e Economía, Instituciones y Políticas Públicas (La Ley, 2011).
}

E-mail:mkrause@derecho.uba.ar 


\section{INTRODUÇ̃̃o}

Nas últimas décadas, a teoria econômica neoclássica registrou grandes avanços no estudo dos incentivos e da remuneração, também chamado por alguns autores de "Economia dos recursos humanos" ${ }^{1}$. Chegouse, assim, a uma nova compreensão da mecânica da remuneração e introduziu-se uma série de inovações nessa área de estudos. Nesse contexto, viu-se que a maior parte das questões relativas à motivação derivam de problemas no relacionamento entre principal e agente, pressupondo-se que os indivíduos busquem a satisfação de seus próprios interesses e que seja necessário algum tipo de mecanismo que promova o alinhamento desses interesses com aqueles da companhia.

A exemplo de todas as demais teorias econômicas, esta também teve de simplificar seus pressupostos para poder atingir um nível mais alto de formalização e rigor; no que obteve um sucesso considerável quanto à formulação dos problemas, mas muito menor quanto à oferta de soluções, considerando-se o foco limitado da pesquisa ${ }^{2}$.

Em muitos trabalhos nesta área, trata-se dos sistemas de remuneração com o objetivo de complementar a teoria básica segundo a qual cada trabalhador recebe um salário competitivo estipulado pelo mercado, sem, contudo, entrar-se em detalhes quanto à forma dessa remuneração, como ela muda ao longo do tempo e de que modo se explicam os diferentes incentivos ligados às inumeráveis posições e funções ocupadas dentro de uma companhia.

Um dos pressupostos simplificadores é a redução do princípio da maximização da utilidade a um valor pecuniário. Se $x$ é o limite orçamentário de um indivíduo ou a quantidade de riqueza monetária de que este dispõe e $y$, todas as outras variáveis não

\footnotetext{
${ }^{1}$ LAZEAR, Edward P. Personnel Economics. In: The Wicksell Lectures. Cambridge, Mass: The MIT Press, 1996.

${ }^{2}$ Idem. Ibidem., p. 2.
}

pecuniárias que afetam suas preferências, então a função de utilidade toma a forma $u(x$, $y)$. Se não há um "efeito riqueza", sempre se considera que exista um valor de equivalência pecuniária aplicável às variáveis não pecuniárias $(y)$ e, então, a função de utilidade pode ser expressa como $u(x, y)=x+v(y)$, onde $v(y)$ é o equivalente em dinheiro de todas as outras variáveis não pecuniárias que afetam a decisão do indivíduo.

O chamado efeito riqueza é aquela situação em que, dadas duas possíveis decisões diferentes $d_{1}$ e $d_{2}$, existe uma quantia de dinheiro definida, $M$, suficiente para que o indivíduo se manifeste indiferente quanto a qual das duas decisões tomar. Se o sujeito da decisão recebesse antes uma quantia adicional de riqueza, isso não mudaria a quantia necessária para provocar sua indiferença; além disso, ele deve possuir dinheiro suficiente para que os pagamentos exigidos se desloquem da opção menos atraente para a opção preferida.

No universo conceitual específico dos sistemas de remuneração, isso se aplica da mesma forma, convertendo-se os elementos não pecuniários da remuneração em seus equivalentes pecuniários ${ }^{3}$.

Neste artigo, procuraremos mostrar que a perspectiva "austríaca" é o caminho mais profícuo que uma teoria da remuneração deve tomar com vistas a eliminar tal restrição e passar a ter em conta as diferentes reações dos indivíduos "dentro" de uma companhia quando submetidos a cada um desses tipos de incentivo. Isto é, a visão subjetivista do valor

\footnotetext{
${ }^{3}[\ldots]$ as teorias econômicas são plenamente capazes de integrar em seus modelos todos os aspectos da remuneração. Não é necessário que a remuneração assuma formas pecuniárias. A renda psíquica derivada dos benefícios de um cargo, do status, das condições de trabalho, entre outros fatores, são facilmente incorporáveis na análise convencional. $\mathrm{O}$ que distingue a abordagem econômica daquelas de outras disciplinas é o fato de os componentes não pecuniários serem convertidos em seus equivalentes monetários no decorrer da análise. Como resultado disso, os economistas tornam-se aptos a discutir esses fatores de maneira concreta e rigorosa. (Idem. Ibidem., p. 4).
} 
que é própria da Escola Austríaca permite eliminar o pressuposto da heterogeneidade dos agentes e, assim, abre o caminho para uma teoria da remuneração mais realista e elaborada, capaz de levar em conta as preferências subjetivas dos agentes em função de sua remuneração.

\section{I - O Modelo Neoclássico BÁsico}

Seguindo-se um modelo básico de remuneração, costuma-se enunciar que o nível de esforço $e$ escolhido por um empregado pode ser relacionado a uma variável mensurável, por exemplo, em termos de horas de trabalho ou produção; medida que é sempre imperfeita, pois estas podem ser afetadas por circunstâncias alheias à vontade do empregado.

A formalização de variáveis não pecuniárias em seus equivalentes pecuniários iniciou-se com o trabalho de Sherwin Rosen (1938-2001), em que o autor chama "preços hedônicos"4 aos valores implícitos de atributos revelados aos indivíduos através dos preços de diferentes produtos e do número de atributos associados a cada um deles. Nos estudos da remuneração, chamase a isso "diferenciais de remuneração", transformando-se os componentes não pecuniários em seu equivalente pecuniário ${ }^{5}$.

Adam Smith (1723-1790) já enxergava claramente a importância das variáveis pecuniárias e não pecuniárias como componentes daquilo que hoje chamamos

4 ROSEN, Sherwin. Hedonic Prices and Implicit Markets: Product Differentiation in Pure Competition. The Journal of Political Economy, Vol. 82, No. 1. (jan.feb. 1974): 34-55.

5 ROSEN, Sherwin. Substitution and Division of Labour. Economica, Vol. 45 (1978): 235-250; ROSEN, Sherwin. The Theory of Equalising Differences. In: ASHENFELTER, O. \& LAYARD, R. (Orgs.). Handbook of Labor Economics, Vol. 1, Chap. 12. New York: Elsevier Science Publishers, 1986. de remuneração ${ }^{6}$ e explicava as diferenças salariais pelas características diversas de cada cargo. Na base da teoria que mais tarde se desenvolveria estava o reconhecimento de que tais diferenças salariais são necessárias para o nivelamento do conjunto dos atributos pecuniários e não pecuniários entre os diferentes cargos. Com base nisso, ressaltavase que a maximização dos resultados exigia o alinhamento do tipo certo de trabalhador com o tipo certo de companhia, designando-se cada trabalhador para um "nicho" específico, seja dentro de uma empresa, seja entre duas empresas ${ }^{7}$.

Um caso típico disso é a segurança do trabalho. Pode-se "comprar" um certo nível de risco no trabalho mediante o pagamento de um determinado salário, para uma determinada função, ceteris paribus ${ }^{8}$.

6 Os salários em dinheiro e o lucro, na realidade, são extremamente diferentes em toda a Europa, de acordo com os diferentes empregos de mão-de-obra e de capital. Essa diferença tem origem, em parte, em certas circunstâncias ou fatores inerentes aos próprios empregos, fatores esses que, realmente ou ao menos na imaginação das pessoas, respondem por um pequeno ganho pecuniário em alguns, e contrabalançam um grande ganho em outros - e em parte na política vigente na Europa, que em nenhum lugar permite que as coisas ocorram com plena liberdade.

[...]

São cinco as principais circunstâncias que, segundo tenho podido observar, respondem por um pequeno ganho pecuniário em alguns empregos e contrabalançam um ganho grande em outros: primeiro, o caráter agradável ou desagradável dos próprios empregos; segundo, a facilidade e o pouco dispêndio, ou a dificuldade e o alto dispêndio exigidos para a aprendizagem dos empregos; terceiro, a constância ou inconstância desses empregos; quarto, o grau pequeno ou grande de confiança, colocado naqueles que os ocupam; quinto, a probabilidade ou improbabilidade de ter sucesso neles. (SMITH, Adam. A Riqueza das Nações: Investigação Sobre sua Natureza e suas Causas. Tradução de Luiz João Baraúna. São Paulo: Nova Cultural, 1996).

${ }^{7}$ ROSEN. The Theory of Equalising Differences.

8 HÜBLER, Dominik \& HÜBLER, Olaf. The Link between Job Security and Wages: A Comparison between Germany and the UK. SBR, Vol. 62 (jan. 2010): 45-67. 
Quando se trata de incentivos gerados através de remuneração, o modelo básico pressupõe que o nível de esforço $e$ escolhido pelo empregado pode ser medido (em horas de trabalho, por exemplo), mas não pode ser observado diretamente, uma vez que sofre a influência de outros fatores. As observações, portanto, representam mensurações de $e$ distorcidas por fatores aleatórios que fogem ao controle do agente. Por exemplo, o volume de vendas pode fornecer informações relacionadas aos esforços despendidos, mas o resultado é afetado por fatores não relacionados ao nível de esforço do agente. Nesse caso, teríamos:

$$
\text { (1) } \mathrm{V}=e+x
$$

...onde o volume de vendas depende do esforço, bem como de uma variável $x$ não observável separadamente, mas apenas integrada ao resultado geral V. Esse volume pode crescer com o aumento do esforço, mas também com o aumento do consumo, ou como resultado de um concorrente estar passando por dificuldades etc. A variável $x$ não é observável, mas pressupomos que ela esteja relacionada a uma outra que o seja, como a demanda total do setor. A remuneração linear se expressaria pela seguinte fórmula:

$$
\text { (2) } S=B+\beta(V+p y)
$$

Onde $\mathrm{B}$ é o salário-base, $\beta$ é a medida de intensidade do incentivo e $p$, o peso da variável $y$. Como $x$ não é observável, a remuneração consistirá em um salário fixo e uma variável composta da porcentagem das vendas ponderada pela evolução da demanda. Certamente que a remuneração linear não é a única fórmula possível. Os contratos de trabalho incluem outras variáveis, considerando-as como uma série de parâmetros a estipular o nível de esforço esperado do funcionário e a forma como este será remunerado conforme seu desempenho.

A natureza aleatória de $x$ submete o empregado a uma certa quantidade de risco. O modelo básico pressupõe que a capacidade do empregado de assumir riscos é inferior à do empregador, principalmente em médias e grandes empresas; mas se a empresa assumisse todo o risco, o empregado não teria incentivos para buscar os melhores resultados possíveis e não se esforçaria - como acontece quando o salário é fixo e o emprego é totalmente estável.

Devido à diversidade de parâmetros envolvidos em um contrato, estabelecese um equivalente pecuniário que inclui o salário esperado, menos o custo de provisão do esforço necessário, bem como um prêmio de risco ${ }^{9}$. Esses elementos podem ser modificados, mantendo-se o total inalterado - a isso chamamos, anteriormente, "efeito riqueza". De acordo com o princípio de maximização, um contrato eficiente é aquele que especifique parâmetros que maximizem a soma equivalente das receitas, tanto para o empregado como para o empregador. Os contratos, no entanto, são incompletos. Estabelecem apenas o nível de esforço acordado entre as partes como compatível com a remuneração, e vimos que este não pode ser observado diretamente, sendo escolhido pelo empregado, que continuará despendendo esforços enquanto o benefício marginal da remuneração superar o custo marginal.

Segundo se presume nessa análise, o empregador estipula o nível de esforço $e$, e então procura ajustar os parâmetros $B, \beta$ e p para tentar realizar o processo ao menor custo possível; o que é conhecido como "problema da implementação". Deduz-se também que, ao se projetar sistemas de remuneração, o valor total aumenta quando se introduz variáveis de desempenho que reduzam a variabilidade de outros fatores ( $x$ e $y$ ). Se $x$ e $y$ forem independentes, então não fará sentido usar $y$. Se, no entanto, a covariância for

\footnotetext{
${ }^{9}$ Presumindo-se que os valores de $x$ e $y$ sejam zero e que $r$ seja o coeficiente de risco do empregado, a equivalência $\mathrm{e}^{\prime}=\mathrm{B}+\beta \mathrm{e}-\mathrm{C}(\mathrm{e})-1 / 2 \beta^{2} \operatorname{Var}(\mathrm{x}+\mathrm{py})$; (MILGROM, Paul \& ROBERTS, John. Economics, Organization and Management. Englewood Cliffs: Prentice Hall, 1992. p. 217). Há uma fórmula de equivalência também para o empregador, mas dado o foco da presente análise, aqui nos preocupamos apenas com o agente.
} 
positiva, dever-se-á estipular um y negativo para contrabalançar um fator de "sorte" a afetar a quantidade de remuneração total. Da mesma forma, se a covariância for negativa, um $y$ postivo deverá ser estipulado ${ }^{10}$.

Já quanto à intensidade do incentivo, esta dependeria de quatro fatores: o crescimento nos lucros gerado pelo aumento do esforço, a precisão da mensuração do desempenho, a aversão ao risco da parte do agente e o nível de reação deste aos incentivos ${ }^{11}$. Aqui encontramos, pela primeira vez, uma referência à heterogeneidade dos agentes, a qual se introduz no processo na medida em que está relacionada a uma diferença na aversão ao risco, considerando-se que quanto maior a tolerância, menor o risco assumido pelo agente cujos incentivos estão mais intimamente ligados aos resultados. Mas isso é tudo, uma vez que o quarto fator (a reação do agente a incentivos) está ligado às características do emprego e à possibilidade ou impossibilidade de o agente produzir mais como reação a um incentivo; o que, por sua vez, depende de seu poder de ingerência em questões como ritmo de trabalho, cronogramas, ferramentas e equipamentos etc.

O princípio da intensidade do monitoramento ${ }^{12}$ introduz no modelo básico os custos de controle, obtidos pela redução do tamanho dos grupos sob o controle de um supervisor, pela introdução de novas formas de controle de qualidade, ou, ainda, pela verificação da satisfação do cliente. Todas essas alternativas, é claro, implicam um custo. Portanto, a eficiência de seu uso será maior, quanto mais a remuneração do agente estiver vinculada a resultados.

10 HOLMSTROM, Bengt. Moral Hazard and Observability. The Bell Journal of Economics, Vol. 10, No. 1, (Spring 1979): 74-91.

${ }^{11}$ PRENDERGAST, Canice. The Provision of Incentives in Firms. Journal of Economic Literature Vol 37 (1999): 7-63.

${ }^{12}$ MILGROM \& ROBERTS. Economics, Organization and Management. p. 221.
Em último lugar, o princípio da remuneração igual trata do caso em que o empregado tem de desempenhar diferentes tarefas, algumas das quais podem ser medidas com precisão, enquanto outras não podem. Nesse caso, a introdução de um mecanismo de remuneração baseado na mensuração de uma atividade implicaria menor atenção prestada às outras.

Embora o modelo básico sucintamente apresentado leve em conta os incentivos não pecuniários (ainda que apenas através de seu equivalente monetário), os economistas quase sempre se concentraram na análise dos sistemas de recompensa baseados em remunerações pecuniárias ${ }^{13}$. Nesse sentido, foram confrontados por uma série de autores, particularmente do campo da psicologia, bastante críticos em relação aos incentivos pecuniários. Deci apresenta os resultados de um projeto de pesquisa de acordo com o qual a motivação extrínseca - incluindo-se aqui não

${ }^{13}$ Os modelos econômicos de remuneração geralmente assumem que um desempenho superior exige esforços maiores, ou que esse desempenho esteja associado, de alguma outra forma, à desutilidade da parte dos trabalhadores. Quando se trata de fornecer incentivos, esses modelos preveem a existência de sistemas de recompensa que estruturam a remuneração de modo a que a expectativa deutilidade deum trabalhador seeleve conforme a produtividade observada. As recompensas podem assumir muitas formas diferentes, incluindo-se o elogio por parte dos superiores e dos companheiros de trabalho, promessas implícitas de oportunidades futuras de promoção, sentimentos de autoestima provenientes de um maior reconhecimento pelos colegas e do sucesso acima da média no desempenho das tarefas, além de gratificações em dinheiro - no presente e no futuro - relacionadas ao desempenho. Embora reconheçam a possível importância das recompensas não pecuniárias por desempenho, os economistas tendem a concentrar-se nas pecuniárias porque os indivíduos estão dispostos a substituir as recompensas não pecuniárias pelas pecuniárias e porque o dinheiro representa uma demanda por receita em termos gerais e costuma ser mais estimado que o pagamento de seu equivalente em mercadorias ou gêneros (BAKER, George G. ; JENSEN. Michael C. \& MURPHY, Kevin J. Compensation and Incentives: Practice vs. Theory. The Journal of Finance, Vol. XLIII, No. 3 (1988). p. 594). 
apenas pagamentos condicionais em espécie, como também ameaças de punição por mau desempenho ou avaliações negativas - reduz as motivações "intrínsecas"14. Conforme se verificou, pagamentos condicionais não elevavam a motivação, enquanto os incentivos verbais cumpriam esse objetivo. Frederick Herzberg (1923-2000), por sua vez, classifica os incentivos em duas categorias: a dos fatores "motivantes", incluindo $\mathrm{O}$ reconhecimento de metas cumpridas, o próprio cargo, a responsabilidade e o crescimento ou desenvolvimento pessoal; e a dos fatores que buscam evitar a insatisfação, como a política da empresa, a supervisão, as relações interpessoais, as condições de trabalho, o status e a segurança ${ }^{15}$. Com base numa amostragem de 1685 empregados, observou-se que os fatores do primeiro tipo representavam a fonte principal de insatisfação. Mais especificamente, o cumprimento de metas teve um índice de seleção de $40 \%$, o reconhecimento, de $30 \%$, enquanto os salários não chegaram a 10\%. Já para Alfie Kohn, a remuneração pecuniária não é um fator motivador, mas sim uma punição, quando não se recebe um prêmio pela realização de alguma tarefa ${ }^{16}$. Essa punição deteriora as relações de cooperação, ignorando as razões por que os empregados não tiveram o desempenho esperado, desencoraja a assunção de riscos e destrói o interesse do empregado pelo seu trabalho.

Mais recentemente, o debate deslocouse para o campo da economia experimental: Uri Gneeze e Aldo Rustichini descobriram uma relação "não-monotônica" entre o pagamento por peça produzida e um teste

14 DECI, Edward. The Effects of Contingent and Non-contingent Rewards and Controls On Intrinsic Motivation. Organizational Behavior and Human Performance, Vol. 8 (1972): 217-229.

${ }^{15}$ HERZBERG, Frederick. One more time: How do you motivate employees? Harvard Business Review (sep.oct. 1987).

${ }^{16}$ KOHN, Alfie. Why Incentive Plans Cannot Work. Harvard Business Review, Sep-Oct 1993. de inteligência ${ }^{17}$. Quando o pagamento era por peça, o desempenho mostrava-se inferior a quando não havia o pagamento, ainda que o pagamento por peça representasse um resultado melhor quando superior. Para os autores, o método de pagamento (sem pagamento, pequenos pagamentos, ou grandes pagamentos) representava uma pista quanto à meta do experimentador. Quando os participantes recebiam o pagamento antes do experimento, interpretava-se que eles já haviam sido remunerados e que deveriam esforçar-se o máximo possível. Se, entretanto, o pagamento fosse "por peça", interpretava-se que o objetivo do experimento era o dinheiro e o resultado mostrava-se pior quando o valor pago era baixo, embora melhorasse quando o valor pago era alto. Para Roland Bénabou e Jean Tirole, o experimento demonstra o "efeito deslocamento" dos incentivos pecuniários sobre os não pecuniários ${ }^{18}$. No universo conceitual de um modelo de tipo "principal - agente", o principal conhece melhor as capacidades do agente ou as características do emprego, e ambos conhecem essa diferença. Nesse caso, o incentivo pecuniário vinculado à produtividade seria um mau sinal, pois apontaria para a necessidade de oferecer incentivos monetários devido à baixa capacidade do agente ou às características negativas do emprego.

Roberta Dessi e Aldo Rustichini realizaram uma pesquisa para verificar a validade dessas duas teorias ${ }^{19}$. Conforme afirmam os autores em suas conclusões, para tarefas que demandam talento, é melhor "não haver pagamento algum" quando a motivação intrínseca for suficientemente alta; pois,

${ }^{17}$ GNEEZY, Uri \& RUSTICHINI, Aldo. Pay Enough or don't Pay at All. Quarterly Journal of Economics, Vol. 115, No. 3 (2000): 791-810.

${ }^{18}$ BÉNABOU, Roland \& TIROLE, Jean. Intrinsic and Extrinsic Motivation. Review of Economic Studies, Vol. 70 (2003): 489-520.

19 DESSI, Roberta \& RUSTICHINI, Aldo. Work for Image and Work for Pay. IDEI, Relatório de trabalho No. 683 (Setembro de 2011). 
nesse caso, incentivos pecuniários suscitam demasiado empenho e pouco desempenho. Por outro lado, deve-se pagar "o bastante" quando os estímulos intrínsecos forem insuficientes para motivar os indivíduos talentosos.

Em uma pesquisa realizada por Sebastian Kube, Michel André Maréchal e Clemens Puppe em um ambiente natural, contrataramse empregados para catalogar livros em uma biblioteca por um período limitado de tempo, oferecendo-se 12 euros por hora ${ }^{20}$. Num segundo momento, foi implementado um aumento salarial imprevisto de quase $20 \%$. Posteriormente, substitui-se o aumento por um presente de valor equivalente a este e, finalmente, numa quarta fase, os empregados foram informados do valor exato em dinheiro do presente recebido. Os resultados demonstraram que o aumento no valor pago teve um impacto insignificante sobre a produtividade dos empregados, enquanto o presente de valor equivalente gerou um aumento de $30 \%$ na produção, que perdurou por todo o período. O resultado mantevese inalterado quando se informou aos empregados o valor do presente. $\mathrm{O}$ contraste comportamental foi confirmado por um questionário distribuído em seguida, através do qual se descobriu que o presente tende muito mais a sinalizar boas intenções do que o aumento salarial, o que leva os funcionários a retribuírem com o aumento da produtividade. É o valor simbólico do presente que gera a reação. Resultados semelhantes foram obtidos por James Heyman e Dan Ariely com 614 estudantes de Berkeley e do MIT ${ }^{21}$. Uri Gneezy

\footnotetext{
${ }^{20}$ KUBE, Sebastian; MARÉCHAL, Michel André \& PUPPE, Clemens. The Currency of Reciprocity: GiftExchange in the Workplace. Working Paper Series, Relatório de trabalho No. 377. Institute for Empirical Research in Economics. Universidade de Zurique (2008).

21 Duas experiências envolvendo comportamento real e uma envolvendo comportamento hipotético foram conduzidas em um ambiente genérico em que os indivíduos participavam de jogos em que se tinha apenas uma chance de vencer. $\mathrm{O}$ pagamento
}

e John List, por sua vez, confirmam o mesmo resultado com um experimento semelhante ${ }^{22}$; ressaltando, entretanto, que tal conduta persiste após o período inicial, embora os resultados posteriores sejam iguais.

Na mesma trilha do já citado Frederick Herzberg, outro ramo desse campo de estudos enfatiza o ato de "projetar" as tarefas como um importante fator motivador. J. Richard Hackman (1940-2013) e Greg R. Oldham desenvolveram o "modelo das características do emprego", afirmando que estas representam um incentivo intrínseco: quando o trabalho é "importante", os empregados se comprometem mais, concentram-se mais nos objetivos, prestam mais atenção, raciocinam mais cuidadosamente e trabalham mais ${ }^{23}$.

A réplica dos economistas a essa contestação traz à tona questões interessantes. Para

era garantido, ou prometido com confiabilidade, antes de o esforço ser realizado. Os resultados dão respaldo à perspectiva que admite a existência de dois mercados distintos: quando o pagamento era oferecido na forma de presentes (doces), ou quando não se o mencionava, os esforços pareciam advir de motivos altruísticos e eram altamente insensíveis à magnitude do pagamento. Em contrapartida, quando o pagamento era em dinheiro, os esforços pareciam derivar da reciprocidade e se revelavam sensíveis à magnitude da quantia paga. Finalmente, em um mercado misto (quando o pagamento era na forma de presentes, mas o custo destes era informado), a simples menção do pagamento pecuniário era suficiente para deslocar a visão que se tinha do relacionamento, de uma perspectiva mais social para uma outra, mais mercadológica e monetária. Isto é, o próprio dinheiro pode representar uma indicação do tipo de intercâmbio do qual os indivíduos se consideram participantes, o que, por sua vez, influencia sua disposição para exercer esforço (HEYMAN, James \& ARIELY, Dan. Effort for Payment: A Tale of Two Markets. Psychological Science, Vol. 15, No. 11 (November 2004): 787-793. p. 791).

${ }^{22}$ GNEEZY, Uri \& LIST, John A. Putting Behavioral Economics to Work: Testing for Gift Exchange in Labor Markets using Field Experiments. Econometrica, Vol. 74, No. 5 (September 2006): 1365-1384.

${ }^{23}$ HACKMAN, J. Richard \& OLDHAM, Greg R. Motivation through the design of work: test of a theory. Organizational Behavior and Human Performance, Vol. 16, No. 2 (1976): 250-279. 
George G. Baker, Michael C. Jensen e Kevin J. Murphy, as críticas aos sistemas de pagamento por desempenho não provam que estes sejam ineficazes, mas sim que são eficazes demais, pois motivam as pessoas a fazer exatamente aquilo que se mandou que elas fizessem; embora às vezes gerem conseqüências imprevistas, por ser difícil especificar o que as pessoas devem fazer e, logo, como se deve medir seu desempenho ${ }^{24}$. Segundo G. Bennett Stewart III, o sistema de preços faz com que os recursos escassos sejam distribuídos eficientemente, ao recompensar quem conserva e penalizar quem não reage aos estímulos. Nesse contexto, pergunta o autor: "será verdade que as pessoas reagem a incentivos pecuniários quando gastam sua renda, mas não quando a ganham, como parece pensar Kohn?" 25.

Ao comentar alguns estudos sobre criatividade realizados com artistas, Amabile et al e Amabile observam que, embora os artistas realmente prefiram trabalhos não encomendados, o que mais afeta a criatividade são as cláusulas restritivas que podem aparecer no contrato quando se encomenda um trabalho ${ }^{26}$. Exceto por esse problema, os artistas são receptivos a esse tipo de trabalho:

Kohn documenta com precisão as provas de que as recompensas podem comprometer a criatividade. Não menciona, contudo, as provas de que as recompensas tangíveis podem, na verdade, aumentar a criatividade em certas circunstâncias, principalmente quando o foco principal do indivíduo é o valor intrínseco do próprio trabalho ${ }^{27}$.

\footnotetext{
${ }^{24}$ BAKER ; JENSEN \& MURPHY. Compensation and Incentives: Practice vs. Theory. p. 597.

25 STEWART, G. Bennett III. Rethinking Rewards. Harvard Business Review, Perspectives, (nov.-dec. 1993). p. 4.

26 AMABILE, Teresa M.; HENNESSEY, Beth Ann \& GROSSMAN, Barbara S. Social Influences on Creativity: The Effects of Contracted-for Reward. Journal of Personality and Social Psychology, Vol. 50, No. 1 (1986): 14-23; AMABILE, Teresa M. Rethinking Rewards. Harvard Business Review, Perspectives (nov.-dec. 1993).

${ }^{27}$ Idem. Ibidem., p. 7.
}

Entre os trabalhos mais recentes que defendem o pagamento por desempenho, pode-se citar o ensaio de Edward P. Lazear e Kathryn L. Shaw ${ }^{28}$ e o estudo de Edward P. Lazear, Steffen Altmann e Klaus F. Zimmermann ${ }^{29}$.

\section{II - A Teoria do Trabalho DA Escola Austríaca e a Heterogeneidade dos Agentes}

Todo esse debate, no entanto, concentrase nos incentivos desde o ponto de vista da "oferta", direcionados a um conjunto homogêneo de agentes e com vistas a melhorar o desempenho; subestimando-se os incentivos tomados desde a perspectiva da "demanda". Uma visão "austríaca" nos levaria a considerar o problema da heterogeneidade.

Desde o surgimento da Escola Austríaca, seus economistas sempre se preocuparam com a remuneração do trabalho. Mais especificamente, desenvolveram a teoria da utilidade marginal e da produtividade marginal do trabalho, para explicar a remuneração do trabalho em geral ${ }^{30}$. O primeiro a confrontar as teorias do valortrabalho foi Eugen von Böhm-Bawerk (18511914), no Livro V de sua obra Capital e Juros, onde critica as teorias do juro baseadas no trabalho, as quais classificava em três grupos: o grupo inglês de James Mill (17731836) e John Ramsey McCulloch (1789-1864), daqueles que pretendem explicar o juro e, ao

\footnotetext{
${ }^{28}$ LAZEAR, Edward P. \& SHAW, Kathryn L. Personnel Economics: The Economist's View of Human Resources. NBER, Relatório de trabalho No. 13653. Cambridge, MA: National Bureau of Economic Research, 2007.

29 LAZEAR, Edward P.; ALTMANN, Steffen \& ZIMMERMANN, Klaus F. Inside the Firm: Contributions to Personnel Economics. Oxford: Oxford University Press, 2011.

${ }^{30}$ BOETTKE, Peter J. \& LUTHER, William J. Labor Economics from an Austrian Perspective. Relatório de Trabalho No. 12-4. Departamento de Economia da Universidade George Mason (2012).
} 
mesmo tempo, sustentar uma teoria do valortrabalho; o grupo francês de Jean Gustave Courcelle-Seneuil (1813-1892), segundo o qual há dois tipos de trabalho, o "vigoroso" e o "poupador", caracterizado pela "recusa de qualquer gratificação por um determinado período de tempo"; e o grupo alemão (formado pelos ditos socialistas de cátedra ${ }^{31}$ ), inspirado por Johann Karl Rodbertus (18051875), a quem Böhm-Bawerk dedica uma seção inteira do Livro VI, seguida de sua crítica a Karl Marx (1818-1883).

Depois disso, foi Ludwig von Mises (1881-1973) quem aprofundou essas idéias em um capítulo (No XXI, "Trabalho e Salários") caracterizado por uma perspectiva claramente subjetivista do início ao fim. Considerando a "desutilidade do trabalho", Mises fornece quatro razões (subjetivas) por que um indivíduo a superaria: para manter sua mente e seu corpo fortes (como quando se pratica um esporte), para servir a Deus, para evitar maiores inconvenientes ou "porque prefere o produto que é capaz de obter com o seu esforço à desutilidade do trabalho e aos prazeres do ócio" ${ }^{\prime 2}$. Os três primeiros tipos de trabalho são gratificantes por si mesmos e Mises os chama de "introvertidos", enquanto o quarto é dito "extrovertido". Para Mises, apenas o último diz respeito à "cataláxia". Isso inclui a "alegria" de realizar um certo trabalho, não como "bem de consumo" em si mesmo, mas sempre como uma forma de gratificação indireta, cujas fontes são: "a antecipação doprazer representado pelo reconhecimento de um trabalho bem feito e sua correspondente remuneração", "o prazer da experiência estética proporcionado pela sua habilidade e pela sua obra"; o "prazer por ter superado com êxito o esforço e aborrecimento necessários à sua execução"; e a satisfação de "determinados desejos", como os eróticos.

\footnotetext{
31 "Katheder-socialisten" em alemão. (N. do T.)

${ }^{32}$ Os trechos traduzidos aqui seguem a seguinte edição brasileira: MISES, Ludwig von. Ação Humana: Um Tratado de Economia. Trad. Donald Stewart Jr. São Paulo: Instituto Ludwig von Mises Brasil, 3ª ed., 2010. p. 588.
}

As condições necessárias ao surgimento do prazer podem ser consideradas mais "homogêneas" no caso da primeira categoria e da terceira, menos um pouco no caso da segunda e menos ainda para a quarta.

Não obstante, conforme afirmaremos aqui, mesmo essas condições mais "homogêneas" devem ser consideradas "heterogêneas" entre diferentes agentes, e isso também tem a ver com a evolução recente das relações industriais. Para Mises, o industrialismo não se interessou em aumentar a alegria do trabalho. Como forma de incentivar o trabalhador, o sistema fiou-se no progresso material advindo da remuneração pecuniária. Mas sabemos que isso mudou.

Mises sustenta que a "alegria" não faz as pessoas trabalharem melhor, pois o que elas querem é gratificação mediata do trabalho e "A única maneira de fazer um homem trabalhar mais e melhor é pela oferta de uma maior recompensa" ${ }^{\prime \prime}$, embora uma recompensa possa ser pecuniária ou não. Além disso, sua análise inclui claramente a "heterogeneidade" das condições de trabalho: "Não existe um tipo uniforme de trabalho ou um nível geral de salários. O trabalho varia em qualidade e cada tipo de trabalho presta serviços diferentes" ${ }^{34}$. Até aqui, essa heterogeneidade do trabalho não difere daquela da perspectiva neoclássica. Ainda assim, uma justificação coerente da valoração subjetiva deve implicar a heterogeneidade na demanda por diferentes tipos de remuneração.

No capítulo supracitado, Mises apresenta toda uma gama de perspectivas clássicas e austríacas acerca de diversas questões que envolvem o trabalho: a determinação dos salários enquanto fator de produção como qualquer outro, a conexão entre todos os tipos de mão-de-obra e de salários através do mercado, a suposta "combinação" entre os empregadores para manter baixos os salários, o desemprego cataláctico e o institucional, os salários brutos e líquidos, os salários e a subsistência, o papel dos sin-

\footnotetext{
${ }^{33}$ Idem. Ibidem., p. 592.

${ }^{34}$ Idem. Ibidem., p. 593.
} 
dicatos, a oferta de mão-de-obra e a Revolução Industrial.

Os estudos mais recentes da Escola Austríaca são mormente empíricos ${ }^{35}$ e tratam do impacto do salário mínimo instituído por lei, bem como da questão da heterogeneidade, mas desde uma perspectiva diferente daquela aqui adotada. "Os economistas da Escola Austríaca costumam enfatizar fortemente que a força de trabalho se compõe de agentes heterogêneos. No contexto das diferenças salariais entre o Norte e o Sul dos Estados Unidos, Don Bellante recorre à heterogeneidade da mãode-obra para explicar a alta correlação entre a imigração e a emigração entre as duas regiões $^{36}$. Por presumirem a força de trabalho como homogênea, muitos observadores ficavam intrigados com o fato de a emigração do Sul (região de salários mais baixos) era folgadamente compensada pela emigração do Norte (onde os salários eram mais altos). Em contraposição, para Bellante, os trabalhadores - cujos perfis se caracterizam por combinações específicas de trabalho bruto, educação formal, treinamento profissional e experiência - mudam-se para áreas onde o salário real é mais alto para eles (e não para onde o salário seja mais alto em média) ${ }^{37}$. Assim, os deslocamentos cruzados da força de trabalho observados aumentam a eficiência mediante o aprimoramento do amálgama de tipos de mão-de-obra em cada região.

Posteriormente, Peter J. Boettke e William J. Luther apresentam seu próprio modelo "austríaco" dos mercados de trabalho, que trata dos custos de prospecção de um trabalhador com base em um modelo desenvolvido por Stigler e que pressupõe um processo competitivo de mercado $^{38}$.

\footnotetext{
${ }^{35}$ BOETTKE \& LUTHER. Labor Economics from an Austrian Perspective. p. 15.

${ }^{36}$ BELLANTE, Don. The North-South Differential and the Migration of Heterogeneous Labor. American Economic Review, Vol. 69, No. 1 (1979): 166-175.

${ }^{37}$ Idem. Ibidem.

38 BOETTKE \& LUTHER. Labor Economics from an Austrian Perspective. p. 21.
}

O modelo não leva em conta questões de remuneração, mas passa direto à consideração do desemprego não-cíclico e cíclico (neste último caso, introduz-se ali a teoria dos ciclos econômicos, da Escola Austríaca).

\section{III - Uma Visão "AustríacA" DA Remuneração}

Para além de todos os subsídios apresentados, procuramos sustentar aqui que uma contribuição austríaca à teoria da remuneração deve ressaltar a heterogeneidade dos agentes.

Do ponto de vista "neoclássico", a heterogeneidade advém do fato de que as empresas, ao proclamarem sua cultura interna e seu sistema de remuneração, entre outras coisas, podem desencadear um processo imperfeito de auto-seleção da parte das pessoas interessadas em trabalhar com elas. Ao fim, então, terminam contratando agentes que nutrem preferências preconcebidas de diversos tipos $^{39}$, quando não conseguem contratar com vistas a um resultado específico.

Os estudiosos da área não costumam tratar muito desse tipo de heterogeneidade e, quando o fazem, consideram apenas as diferenças de habilidade ${ }^{40}$ e seu possível impacto sobre o sistema de planejamento da remuneração; ou as reações gerais dos indivíduos durante o desempenho de certas tarefas e funções, embora os incentivos pecuniários só exerçam efeito sobre alguns deles ${ }^{41}$.

\footnotetext{
${ }^{39}$ PRENDERGAST, Canice. Intrinsic Motivation and Incentives. American Economic Review, Papers \& Proceedings, Vol. 98, No. 2 (2008): 201-205.
}

40 BALAFOUTAS, Loukas ; DUTCHER, Glenn ; LINDNER, Florian \& RYVKIN, Dmitry. To reward the best or to punish the worst? A comparison of two tournament mechanisms with heterogeneous agents. Working Papers in Economics and Statistics, 2012-08. University of Innsbruck (2012).

${ }^{41}$ Em muitas tarefas, a presença de incentivos financeiros e sua quantidade parecem realmente 
$\mathrm{Na}$ análise daquele a que se costuma chamar "modelo hedônico" ${ }^{42}$, chega-se a tratar dos benefícios pecuniários e da heterogeneidade do agente, mas apenas como elementos externos que afetam a empresa. Sua manifestação permite que os agentes se selecionem conforme as próprias preferências, mas mesmo neste caso, e considerandose a diversidade de tarefas dentro de uma empresa, a heterogeneidade será inevitável. A necessidade de introduzir a análise da heterogeneidade "dentro" das empresas parece ser um fato incontornável.

afetar o desempenho geral, sobretudo quando exigem capacidade de julgamento e quando o esforço é influenciado por incentivos (o que se mede independentemente, por exemplo, através do tempo de reação da pessoa e da dilatação de sua pupila) e quando o aumento dos esforços melhora o desempenho. Entre os casos desse tipo, estão as tarefas de memorização ou rememoração (nas quais o ato de prestar atenção é de grande ajuda); as de pareamento de probabilidades e aprendizagem probabilística envolvendo múltiplos sinais (em que a capacidade de registrar cuidadosamente os testes anteriores torna mais precisas as previsões); e as tarefas 'burocráticas' (por exemplo, compilar palavras e montar objetos), tão triviais que a recompensa pecuniária leva a pessoa a aplicar-se persistentemente em sua execução, mesmo depois de a motivação se esgotar. Para inúmeras tarefas, os incentivos não fazem diferença, provavelmente por haver motivação intrínseca suficiente para garantir um bom desempenho, ou então por ser inútil esforçarse mais, o que acontece quando a tarefa é difícil demais ou tem um limite de retorno proporcional. Para outras tarefas, os incentivos podem ser mesmo prejudiciais. Sua intensificação pode levar as pessoas a sobreaprenderem uma heurística (no caso de tarefas de resolução de problemas envolvendo criatividade), a reagir de forma exagerada às informações recebidas (no caso de algumas tarefas de previsão), ou a exercerem 'esforço demais' em circunstâncias nas quais bastaria um pequeno esforço habitual (asfixia durante a prática de esportes). O mesmo acontece quando a excitação causada pelo incentivo intensifica a autoconsciência da pessoa (por exemplo, no caso do aluno que fica ansioso na hora de fazer uma prova). (CAMERER, Colin F. HOGARTH, Robin M. The Effects of Financial Incentives in Experiments: A Review and CapitalLabor-Production Framework. Journal of Risk and Uncertainty, Vol. 19, No. 1-3 (1999): 7-42; 489-520. p. 1.)

${ }^{42}$ LAZEAR \& SHAW. Personnel Economics: The Economist's View of Human Resources.
Nossa hipótese essencial quanto a esse problema é que os agentes se caracterizam necessariamente pela heterogeneidade no que concerne a suas preferências quanto aos diferentes sistemas de motivação e remuneração; e isso, por sua vez, exercerá grande impacto sobre a eficiências desses sistemas. À parte o debate sobre qual tipo de incentivo é preferível, se o pecuniário ou o não pecuniário, sempre haverá, dentro de uma empresa, agentes mais motivados por um ou outro desses tipos de incentivo, ou por diferentes combinações deles. Nesse sentido, o sistema de motivação e remuneração mais "eficiente" será aquele que promova o mais alto grau de esforço da parte do agente, para cumprir as metas estipuladas pelo principal. Um sistema geral se aproximará das condições ideais, mas nunca satisfará todas as preferências individuais. Isso só seria possível com um sistema que as levasse em conta e que se adaptasse a elas.

Um sistema como este enfrentaria o problema das limitações do conhecimento ${ }^{43}$. Desenvolver um sistema de motivação e remuneração adaptado às preferências individuais de cada agente seria não apenas altamente dispendioso para uma empresa, como também lhe faltaria o conhecimento necessário para tanto ${ }^{44}$. Essas limitações de conhecimen-

${ }^{43}$ HAYEK, Friedrich A. The Use of Knowledge in Society. American Economic Review, Vol. XXXV, No. 4 (1945): 519-530. Em português, o artigo foi publicado como HAYEK, F.A. O Uso do Conhecimento na Sociedade. Trad. Philippe A. Gebara Tavares. MISES: Revista Interdisciplinar de Filosofia, Direito e Economia, Vol. I. No. 1 (jan.-jun. 2013): 153-162.

${ }^{44} \mathrm{O}$ caráter peculiar do problema da ordem econômica racional é determinado precisamente pelo fato de que o conhecimento das circunstâncias, do qual devemos fazer uso, nunca existe de forma concentrada e integrada, mas apenas como pedaços dispersos de conhecimento incompleto e frequentemente contraditório que todos os indivíduos isolados possuem. O problema econômico da sociedade não é, portanto, somente um problema de como alocar recursos "dados" se por um "dado" entende-se aquilo que é dado a uma única mente que resolveria reflexivamente o problema posto pelos "dados de input". É mais uma questão de como assegurar o melhor uso dos recursos 
to não implicam, entretanto, que o principal deva excluir qualquer tentativa de alinhar os métodos de incentivo de cada empregado com aqueles da empresa em geral. Da mesma forma, o caráter disperso do conhecimento não impede a existência de um sistema designado a transmiti-lo, por mais imperfeito que este seja. Esta é a função do sistema de preços, no qual as preferências dos consumidores e as dos produtores se revelam e transmitem informações que permitem uma coordenação entre as decisões desses dois agentes.

No que diz respeito ao mercado externo, portanto, a heterogeneidade das preferências permitirá somente a existência de sinais que os agentes usarão para selecionar a si mesmos. Por ora, a única maneira conhecida de fazer isso chama-se "menu de contratos".

\section{IV - Menu de Contratos}

Os problemas descritos acima costumam ser apresentados - acertadamente, a nosso ver - como parte da necessidade de obter, dos agentes, informações "privadas" às quais o principal não tem acesso, tais como o potencial de desempenho em determinada tarefa, ou os resultados alcançáveis de diferentes projetos. Quanto ao uso de tais informações privadas, dois mecanismos são propostos: os menus de contratos e a administração por me$\operatorname{tas}^{45}$. No segundo caso, o agente e o principal (podendo este ser um supervisor que, por sua vez, é um agente perante outros níveis da estrutura hierárquica) negociam entre si alguns critérios e parâmetros de avaliação do desempenho do primeiro.

No que se refere ao agente, o menu de contratos é considerado um meio de revelar

conhecidos para todos os membros da sociedade, para fins cuja importância relativa apenas estes indivíduos conheceriam. Ou, para sintetizar, este é um problema sobre a utilização do conhecimento que não é dado a ninguém em sua totalidade (Idem. Ibidem. p. 154).

${ }^{45}$ MILGROM \& ROBERTS. Economics, Organization and Management. p. 401. informações privadas, mas não preferências individuais. Descobrir quais são essas preferências é uma tarefa não apenas muito dispendiosa, como praticamente impossível, dada a natureza subjetiva destas e a escassez de relações de troca que as revelem. Ainda assim, e embora também tenha o seu custo, o menu representa uma solução alternativa, ao propor justamente o estabelecimento de relações de troca.

Os planos existentes são geralmente conhecidos como de "estilo cafeteria", ou planos de benefícios flexíveis, dada a chance de escolher entre um menu de opções oferecido ${ }^{46}$. Um plano desse tipo é oferecido, por exemplo, pela Universidade de Delaware, que dá a seus funcionários "Udollars" a serem gastos em uma pletora de benefícios não pecuniários. Há até mesmo a possibilidade de comprar mais benefícios do que o permitido pela quantidade de "Udollars" recebida, pagando-se o excedente em dólares ainda isentos de impostos. Se o empregado gastar menos que os "Udollars" que possui, recebe a diferença também em dólares ainda isentos ${ }^{47}$.

Este, contudo, não é o único setor em que se pode dar opções aos empregados. Já mencionamos aqui que o ato de "projetar" a tarefa pode ser motivador para o agente, e nesse caso há também muita variedade, conforme vimos. A empresa de consultoria McKinsey, organiza um torneio em parceria com a Management Innovation and eXchange, de Gary Hammel, e a Harvard Business Review. Na edição de 2012, um dos vencedores foi um grupo da Microsoft e o prêmio foi a possibilidade de os membros do grupo escolherem sua próxima tarefa.

46 "Implementing a Cafeteria-style benefits plan": http://www.cbsnews.com/8301-505125 16251064280/implementing-a-cafeteria-style-benefitsplan/. Ver também BAYTOS, L. M. The Employee Benefit Smorgasbord: Its Potential and Limitations. Compensation Benefits Review, Vol. 2, No. 1 (January 1970): 16-28.

${ }^{47} \mathrm{http}: / / \mathrm{www} . u d e l . e d u / E x e c V P /$ policies personnel 44-73.htm 
Outro exemplo semelhante é o que acontece na Semco, uma empresa brasileira ${ }^{48}$.

Um dos motivos por que as empresas relutam em adotar sistemas como esses são os altos custos administrativos e contábeis. Outra razão é que uma parte dos benefícios concedidos vêm sob a forma de seguros eé mais difícil fazer uma estimativa deles, pois não se sabe antecipadamente quantos empregados os escolherão. Mas não se trata de um problema insolúvel. Os custos administrativos podemse reduzir através de iniciativas inovadores por parte da empresa, ou pela terceirização, no caso dos fornecedores. Estes, entretanto, geralmente são afetados também por uma grande quantidade de regulamentações trabalhistas e fiscais ${ }^{49}$.

\section{Conclusão}

A adoção de uma visão "austríaca", fundada no valor subjetivo, das preferências concernentes aos tipos de incentivo, e a introdução da heterogeneidade dos agentes na análise dos sistemas de remuneração adotados pelas empresas, tudo isso nos permite ter em conta as diferentes preferências dos agentes quanto aos componentes pecuniários e não pecuniários, excluindo-se assim a suposta equivalência monetária de ambos.

Essa diversidade traz à tona o problema das limitações informacionais e da impossibilidade de o principal conhecê-las em cada caso específico, posto não haver relações de troca que as revelem.

Essas trocas podem resultar da implementação de um menu de contratos que permita uma melhor adaptação às preferências

48 SIEHL, Caren ; KILLIAN, Delly \& PEREZ, Francisco. Ricardo Semler and Semco S.A. Harvard Business Review Case. Thunderbird School of Global Management (1999).

49 ATCHISON, Thomas J. ; BELCHER, David W. \& THOMSEN, David J. Internet-Based Benefits \& Compensation Administration. ERI Economic Research Institute (2010). individuais e um nível mais elevado de eficiência, ou de qualquer outro mecanismo projetado pelos empreendedores. No entanto, até o presente momento, a gestão de um sistema assim é dispendiosa em si mesma, mais que a de um outro que não leve em conta todos esses fatores. As limitações informacionais implicam custos potencialmente elevados. Uma empresa só adotará sistemas desse tipo quando os benefícios em matéria de produtividade forem maiores que os custos de sua implementação. Na medida em que esses custos se reduzam, o emprego de tais sistemas se tornará mais amplamente difundido, ou então se desenvolverão outras alternativas. Nesse sentido, a maioria das leis trabalhistas funciona como barreiras à inovação empresarial no campo da remuneração.

A Escola Austríaca fornece todo um aparato conceitual para a análise da diversidade das preferências e para a exclusão da homogeneidade dos agentes como pressuposto teórico. Os indivíduos são diferentes entre si e também avaliam de formas diversas os tipos de incentivo a que são submetidos. Já é tempo de a teoria da remuneração avançar, passando a levar em conta essa diversidade no interior das organizações. cos 